\title{
Pengaruh Lingkungan Kerja Dan Motivasi Terhadap Kinerja Karyawan Pada PT SUNRISE POLYBAG
}

\author{
Lewis Chanderson dan Nyoman Suprastha \\ Program Studi Manajemen Fakultas Ekonomi Universitas Tarumanagara, Jakarta \\ Email: Chandersonl@yahoo.com
}

\begin{abstract}
The purpose of this study is to find out and analyze the influence of work environment and motivation on employee performance ar PT Sunrise Polybag. This research was conducted by probability sampling method with a type of purposive sampling. The researcher distributed questionnaires to 35 employee at PT Sunrise Polybag. Data analysis using PLS SEM analysis. The results of the analysis conclude that work environment has a significant impact on employee performance but motivation has no significant impact on employee performance.
\end{abstract}

Keywords: Work Environment, Motivation, and Employee Performance..

Abstrak: Tujuan penelitian ini adalah untuk mengetahui dan menganalisa pengaruh pengaruh lingkungan kerja dan orientasi terhadap kinerja karyawan pada PT. Sunrise Polybag. Penelitian ini dilakukan dengan metode probability sampling dengan jenis purposive sampling. Peneliti menyebarkan kuesioner kepada 35karyawan PT Sunrise Polybag. Analsisi data menggunakan analisis SEM PLS.Hasil analisis menyimpulkanbahwa lingkungan kerja berpengaruh signifikan terhadap kinerja karyawan sedangkanmotivasi tidak berpengaruh signifikan terhadap kinerja karyawan.

Kata kunci: Lingkungan kerja, Motivasi, dan Kinerja Karyawan.

\section{LATAR BELAKANG}

Era globalisasi yang terjadi memberikan banyak dampak pada perkembangan usaha salah satunya adalah persaingan usaha yang semakin ketat. Persaingan yang ketat ini membuat para pelaku usaha berlomba-lomba untuk memberikan kualitas barang ataupun jasa yang terbaik guna mempertahankan konsumen lama maupun menggaet konsumen baru. Untuk menjadi yang terbaik, maka sebuah unit usaha harus memiliki daya saing maupun keunggulan dibandingkan dengan pesaingnya. Daya saing dan keunggulan ini mampu dimiliki oleh perusahaan dengan dukungan berbagai factor salah satunya adalah kondisi internal dari perusahaan tersebut.

Meskipun sebuah perusahaan memiliki teknologi yang paling canggih, namun tidak dapat dipungkiri bahwa manusia menjadi salah satu factor penting dalam berjalannya suatu perusahaan. Maka dari itu, pentingnya menjaga kualitas sumber daya manusia pada suatu 
perusahaan dapat memberikan dampak pada keunggulan dan daya saing dari perusahaan tersebut.

Dalam membentuk sebuah sumber daya manusia yang unggul dalam suatu perusahaan, maka ada 2 kebutuhan yang harus dipenuhi yaitu kebutuhan materil dan kebutuhan non-materil. Kebutuhan materil dapat berupa kebutuhan yang memiliki bentuk fisik misalnya uang, makanan, pakaian, tempat tinggal, dan lain sebagainya. Sedangkan kebutuhan non-materil dapat berupa penghargaan, pujian, pengakuan, dan lain sebagainya.

Pemenuhan kebutuhan sumber daya manusia dalam sebuah perusahaan tentunya akan memiliki hasil terhadap kualitas sumber daya manusia itu sendiri. Salah satunya adalah dengan meningkatnya kinerja dari setiap individu. Kinerja atau prestasi kerja adalah hasil kerja secara kualitas dan kuantitas yang dicapai oleh seorang pegawai dalam melaksanakan tugasnya sesuai dengan tanggung jawab yang diberikan kepadanya (Mangkunegara, 2006).

Salah satu komponen yang dapat menunjang kebutuhan non materil dari sumber daya manusia yang dimiliki oleh sebuah perusahaan adalah pemberian motivasi. Motivasi merupakan satu penggerak dari dalam hati seseorang untuk melakukan atau mencapai sesuatu tujuan. Motivasi juga bisa dikatakan sebagai rencana atau keinginan untuk menuju kesuksesan dan menghindari kegagalan hidup. Dengan kata lain motivasi adalah sebuah proses untuk tercapainya suatu tujuan. Seseorang yang mempunyai motivasi berarti ia telah mempunyai kekuatan untuk memperoleh kesuksesan dalam kehidupan.

Motivasi secara sederhana dapat dirumuskan sebagai kondisi ataupun tindakan yang mendorong seseorang untuk melakukan suatu pekerjaan atau kegiatan semaksimal mungkin karyawan untuk berbuat dan berproduksi. Peran motivasi adalah untuk mengintensifkan hasrat dan keinginan tersebut, oleh karena itu dapat disimpulkan bahwa usaha peningkatan semangat kerja seseorang akan selalu terkait dengan usaha memotivasinya sehingga untuk mengadakan motivasi yang baik perlu mengetahui kebutuhan kebutuhan manusia (Yulianti, 2015).

Terdapat juga salah satu aspek penting yaitu lingkungan kerja. Lingkungan kerja adalah kehidupan sosial, psikologi, dan fisik dalam yang berpengaruh terhadap pekerja dalam melaksanakan tugasnya. Kehidupan manusia tidak terlepas dari berbagai keadaan lingkungan sekitarnya, antara manusia dan lingkungan terdapat hubungan yang sangat erat. Dalam hal ini, manusia akan selalu berusaha untuk beradaptasi dengan berbagai keadaan lingkungan sekitarnya. Demikian pula halnya ketika melakukan pekerjaan, karyawan sebagai manusia tidak dapat dipisahkan dari berbagai keadaan disekitar tempat mereka bekerja, yaitu lingkungan kerja. Selama melakukan pekerjaan, setiap pegawai akan berinteraksi dengan berbagai kondisi yang terdapat dalam lingkungan kerja.Lingkungan kerja adalah sesuatu yang ada disekitar para pekerja dan yang mempengaruhi dirinya dalam menjalankan tugas-tugas yang dibebankan (Nitisemito, 1992:25). Selanjutnya menurut Sedarmayati (2001:1) lingkungan kerja merupakan kseluruhan alat perkakas dan bahan yang dihadapi, lingkungan sekitarnya dimana seseorang bekerja, metode kerjanya, serta pengaturan kerjanya baik sebagai perseorangan maupun sebagai kelompok. 


\section{KAJIAN TEORI}

\section{Lingkungan Kerja}

Kondisi dan suasana lingkungan kerja yang baik akan dapat tercipta dengan adanya penyusunan organisasi secara baik dan benar sebagaimana yang dikatakan oleh Sarwoto (1991:91) bahwa suasana kerja yang baik dihasilkan terutama dalam organisasi yang tersusun secara baik, sedangkan suasana kerja yang kurang baik banyak ditimbulkan oleh organisasi yang tidak tersusun dengan baik pula.

Pendapat Ahyari (1994:126) bahwa lingkungan kerja adalah berkaitan dengan segala sesuatu yang berada disekitar pekerjaan dan yang dapat memengaruhi karyawan dalam melaksanakan tugasnya, seperti pelayanan karyawan, kondisi kerja, hubungan karyawan di dalam perusahaan yang bersangkutan.Dari pendapat tersebut dapat diterangkan bahwa terciptanya suasana kerja sangat dipengaruhi oleh struktur organisasi yang ada dalam organisasi tersebut.

Menurut Ahyari (1994:128) menjelaskan bahwa, lingkungan kerja dalam perusahaan/instansi dibagi menjadi beberapa aspek pembentukan lingkungan kerja yang lebih terperinci.Adapun beberapa aspek pembentukan lingkungan kerja yang harus diperhatikan adalah pelayanan karyawan, kondisi tempat kerja, dan hubungan antar pegawai dalam organisasi yang bersangkutan. Berdasarkan pendapat Ahyari tersebut, maka penelitian ini pelayanan karyawan, kondisi kerja dan hubungan antar karyawan dalam suatu perusahaan/instansi merupakan aspek-aspek yang digunakan dalam pengukuran variabel lingkungan kerja.

\section{Motivasi}

Menurut Samsudin (2009:81), motivasi adalah proses mempengaruhi atau mendorong dari luar terhadap seseorang atau kelompok pekerja agar mereka mau melaksanakan sesuatu yang telah ditetapkan. Pendapat lain dari Rivai dan Sagala (2009:837), motivasi adalah serangkaian sikap dan nilai-nilai yang mempengaruhi individu untuk mencapai hal yang spesifik sesuai dengan tujuan individu.

Motivasi kerja menurut Robbins (2011:214) bahwa: Motivasi merupakan proses yang berperan pada intensitas, arah, dan lamanya berlangsung upaya individu ke arah pencapaian tujuan. Motivasi kerja menurut Hasibuan (2005:141) bahwa: Motivasi kerja adalah hal yang menyebabkan, menyalurkan, dan mendukung perilaku manusia, supaya mau bekerja giat dan antusias mencapai hasil kerja yang optimal.

\section{Kinerja Karyawan}

Menurut Wibowo (2008: 7), kinerja berasal dari pengertian performance, yaitu sebagai hasil kerja atau prestasi kerja. Kinerja adalah tentang melakukan pekerjaan dan hasil yang dicapai dari pekerjaan tersebut. Selain itu, menurut Amstrong dan Baron dalam Wibowo, (2008: 7), kinerja merupakan hasil pekerjaan yang mempunyai hubungan kuat dengan tujuan strategis organisasi, kepuasan konsumen, dan memberikan kontribusi pada ekonomi.

Sedangkan menurut Mahsun (2006: 25), kinerja (performance) adalah gambaranmengenai tingkat pencapaian pelaksanaan suatu kegiatan/program/kebijakan dalam mewujudkan sasaran, tujuan, misi, dan visi organisasi yang tertuang dalam strategic 
planning suatu organisasi. Istilah kinerja sering digunakan untuk menyebut prestasi atau tingkat keberhasilan individu maupun kelompok individu.Berdasarkan uraian tersebut maka terbentuk kerangka pemikiran dan hipotesis. Model kerangka pemikiran dan hipotesis diuraikan sebagai berikut:

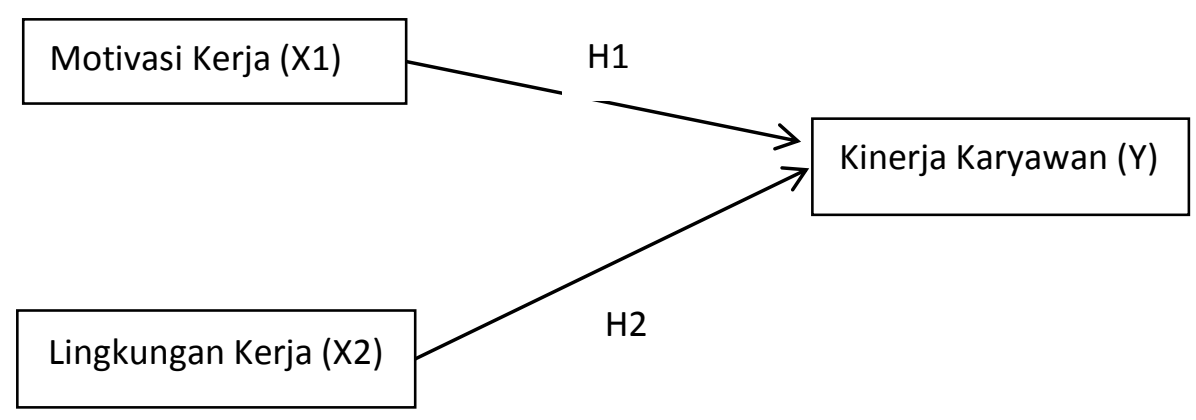

Gambar 1. Kerangka Pemikiran

Berdasarkan kerangka pemikiran di atas, maka dapat dirumuskan hipotesis penelitian sebagai:

$\mathrm{H}_{1}$ : Lingkungan kerja mempengaruhi kinerja karyawan secara positif

$\mathrm{H}_{2}$ : Motivasi Kerja mempengaruhikinerja karyawan secara positif

\section{METODOLOGI}

Metode yang digunakan dalam teknik pemilihan sampel penelitian ini menggunakan metode nonprobability sampling. Metode nonprobability sampling adalah teknik sampling yang tidak menggunakan prosedur seleksi peluang sebaliknya mereka bergantung pada penilaian pribadi dari peneliti. (Maholtra, 2010).Penelitian ini menggunakan teknik random sampling. Sekaran \& Bougie (2013:269) menyatakan bahwa penentuan ukuran sampel yang tepat dalam suatu penelitian adalah 30 - 500 responden atau sebanyak 10 kali lipat variabel yang ingin diteliti dalam suatu penelitian. Maka, jumlah sampel yang diambil oleh peneliti adalah minimal sebanyak 35 karyawan PT. Sunrise Polybag.

\section{HASIL DAN PEMBAHASAN}

Hasil deskripsi subjek penelitian dari 35 responden menunjukkan bahwa terdapat 20 responden pria dan 15 responden wanita. Sebanyak 26 responden adalah karyawan dengan pendidikan terakhir Sarjana/S1. Kemudian responden dengan pendidikan terakhir SMA sebanyak 2 orang. Responden dengan pendidikan terakhir Diploma/ D3 sebanyak 4 orang. Sisanya adalah responden dengan pendidikan terakhir Sarjana/S2 yaitu sebanyak 
3orang.Usia responden antara 21 sampai 30 tahun sebanyak 9 orang. Responden yang berusia antara 31 sampai 40 tahun sebanyak 19 orang. Kemudian yang berusia antara 41 sampai 50 tahun sebanyak 5 orang. Sisanya adalah responden yang berusia antara 51 sampai 60 tahun yaitu sebanyak 2 orang.. sebanyak 18 responden sudah bekerja selama 3 sampai 4 tahun. Kemudian sebanyak 12 responden sudah bekerja selama lebih dari 5 tahun. Sisanya adalah responden yang sudah bekerja selama 1 sampai 2 tahun yaitu sebanyak 5 orang responden.sebanyak 11 responden dengan bidang pekerjaan marketing. Kemudian 7 responden dengan bidang pekerjaan accounting. Sebanyak 6 responden dengan bidang pekerjaan product. Responden dengan bidang pekerjaan HRD sebanyak 2 orang. Sisanya sebanyak 9 responden memiliki bidang pekerjaan selain dari yang disebutkan.

Gambar 1. Hasil Analisis Validitas Konvergen

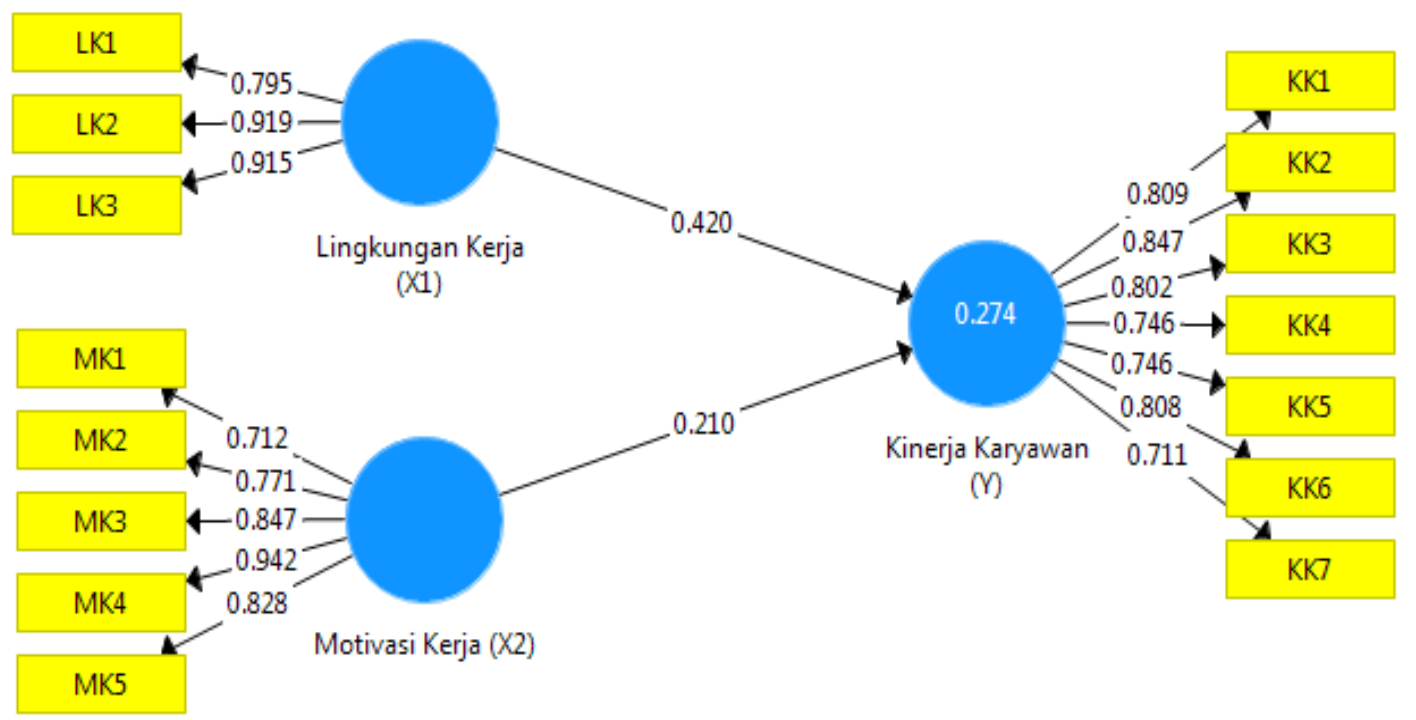

Berdasarkan hasil Average Variance Extracted (AVE) terlihat bahwa seluruh variabel yang diteliti menunjukkan nilai AVE lebih besar dari rule of thumb0,5. Sehingga dapat disimpulkan bahwa indikator-indikator pengukuran suatu konstruk memiliki korelasi tinggi.

Tabel 1. Discriminant Validity (Cross Loadings)

Kinerja Karyawan (Y) Lingkungan Kerja (X1) Motivasi Kerja (X2)

$\begin{array}{llll}\text { KK1 } & \mathbf{0 . 8 0 9} & 0.314 & 0.254 \\ \text { KK2 } & \mathbf{0 . 8 4 7} & 0.361 & 0.418 \\ \text { KK3 } & \mathbf{0 . 8 0 2} & 0.487 & 0.416 \\ \text { KK4 } & \mathbf{0 . 7 4 6} & 0.486 & 0.173 \\ \text { KK5 } & \mathbf{0 . 7 4 6} & 0.237 & 0.181 \\ \text { KK6 } & \mathbf{0 . 8 0 8} & 0.331 & 0.191 \\ \text { KK7 } & \mathbf{0 . 7 1 1} & 0.303 & 0.039\end{array}$




$\begin{array}{lrrr}\text { LK1 } & 0.363 & \mathbf{0 . 7 9 5} & 0.351 \\ \text { LK2 } & 0.427 & \mathbf{0 . 9 1 9} & 0.207 \\ \text { LK3 } & 0.474 & \mathbf{0 . 9 1 5} & 0.258 \\ \text { MK1 } & 0.008 & \mathbf{0 . 7 1 2} \\ \text { MK2 } & 0.078 & 0.163 & \mathbf{0 . 7 7 1} \\ \text { MK3 } & 0.254 & 0.168 & \mathbf{0 . 8 4 7} \\ \text { MK4 } & 0.304 & 0.335 & \mathbf{0 . 9 4 2} \\ \text { MK5 } & 0.366 & 0.43 & \mathbf{0 . 8 2 8}\end{array}$

*Sumber: olahan data SmartPLS 3.00

Berdasarkan tabel 1, diketahui masing-masing dari setiap nilai indikator variabel konstruk dalam mengukur dengan variabel konstruk yang lainnya. Uji validtas diskriminan ini validkarena cross loading pada konstruk yang dimaksud memiliki nilai yang tertinggi dibanding dengan nilai factor loading pada konstruk lain.

Tabel 2. Discriminant Validity (Cross Loadings)

\begin{tabular}{|c|c|c|}
\hline & $\begin{array}{c}\text { Cronbach's } \\
\text { Alpha }\end{array}$ & $\begin{array}{c}\text { Composite } \\
\text { Reliability }\end{array}$ \\
\hline Kinerja Karyawan (Y) & 0.897 & 0.917 \\
\hline Lingkungan Kerja (X1) & 0.85 & 0.91 \\
\hline Motivasi Kerja (X2) & 0.886 & 0.913 \\
\hline
\end{tabular}

Hasil uji reliabilitas pada tabel 4.7 menunjukkan bahwa seluruh cronbach's alpha dan composite reliability masing-masing variabel memiliki nilai $\geq 0,6$ maka dapat disimpulkan bahwa variabel-variabel yang digunakan pada penelitian ini reliabel. 
Gambar 2. Hasil Bootstrapping

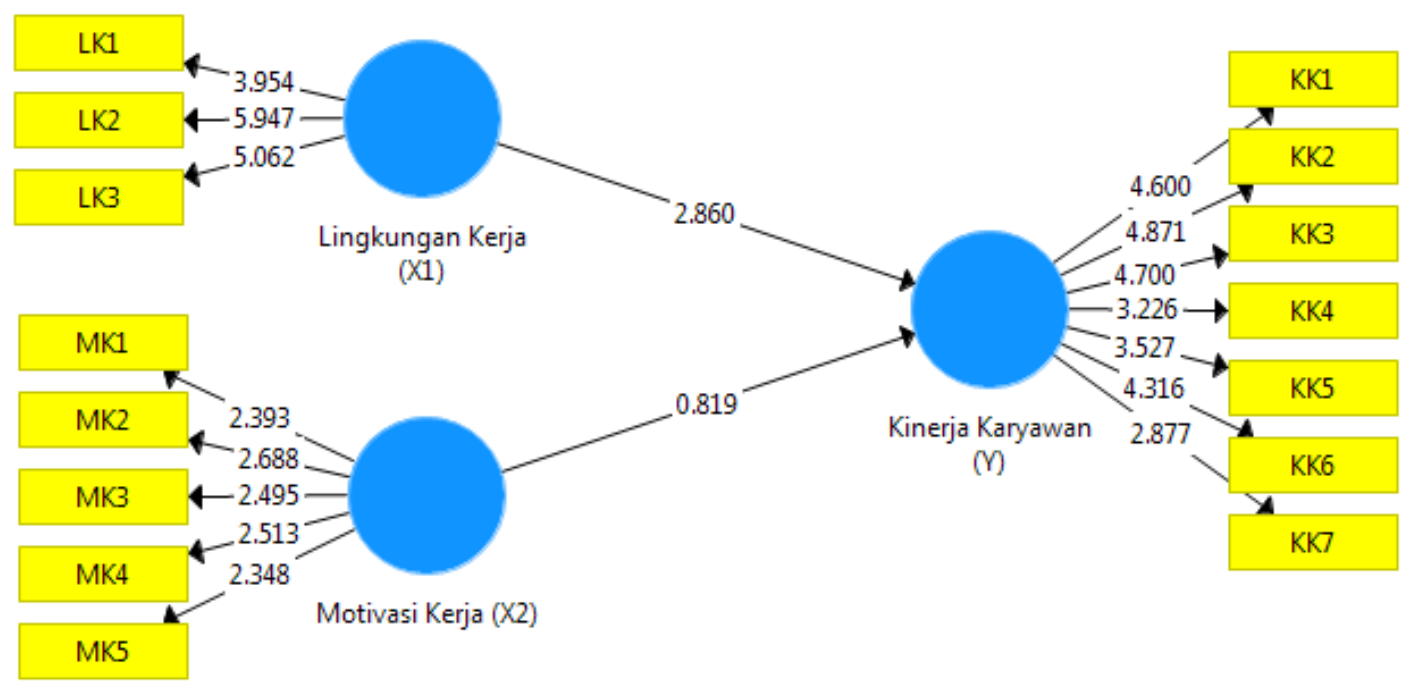

Gambar 2 menunjukkan bahwa nilai prediksi variabel Lingkungan Kerja terhadap kinerja karyawan memiliki nilai path coefficients yang menunjukkan arah positif yaitu sebesar 0,420. Motivasi Kerja terhadap kinerja karyawan menunjukkan arah yang positif yaitu sebsar 0,210.

Tabel 3. Hasil Uji Hipotesis

\begin{tabular}{|l|l|l|l|}
\hline & $\begin{array}{l}\text { Original } \\
\text { Sample } \\
(\mathrm{O})\end{array}$ & $\begin{array}{l}\text { T Statistics } \\
(\mid \mathrm{O} / \mathrm{STDEV})\end{array}$ & $\begin{array}{l}\mathrm{P} \\
\text { Values }\end{array}$ \\
\hline $\begin{array}{l}\text { Lingkungan Kerja (X1) -> Kinerja Karyawan } \\
(Y)\end{array}$ & 0.420 & 2.860 & 0.004 \\
\hline $\begin{array}{l}\text { Motivasi Kerja (X2) -> Kinerja Karyawan } \\
(Y)\end{array}$ & 0.210 & 0.819 & 0.413 \\
\hline
\end{tabular}

*Sumber: olahan data SmartPLS 3.00

\section{a) Uji Hipotesis Pertama}

Perumusan hipotesis yang pertama adalah sebagai berikut:

$\mathrm{H}_{1}$ : Terdapat pengaruh Lingkungan Kerjaterhadap kinerja karyawan.

Berdasarkan hasil pada Tabel 4.3, variabel Lingkungan Kerja terbukti mempengaruhi kinerja karyawan. Hal ini dibuktikan dengan nilai $t$ statistics sebesar 2,860 lebih besar dari cut off value sebesar 1,96 dan $p$ values nya yaitu 0,004 lebih kecil dari cut off value yang ditetapkan yaitu sebesar 0,05 . Sehingga dapat disimpulkan bahwa $\mathrm{H}_{1}$ tidak ditolak.

\section{b) Uji Hipotesis Kedua}

$\mathrm{H}_{2}$ : Terdapat pengaruh Motivasi Kerjaterhadap kinerja karyawan. 
Berdasarkan hasil pada Tabel 4.3, variabel Motivasi Kerjatidak terbukti mempengaruhi kinerja karyawan. Hal inidibuktikan dengan nilai $t$ statistics sebesar 0.413 lebih kecil dari cut off value sebesar 1,96 dan $p$ values nya yaitu 0,413 lebih besar dari cut off value yang ditetapkan yaitu sebesar 0,05 . Sehingga dapat disimpulkan bahwa $\mathrm{H}_{2}$ ditolak.

\section{DISKUSI}

Berdasarkan analisis dan pembahasan sebelumnya, maka dapat diambil beberapa kesimpulan sebagai berikut:

a. Lingkungan kerja berpengaruh signifikan terhadap kinerja karyawan di PT Sunrise Polybag.

b. Motivasi tidak berpengaruh signifikan terhadap kinerja karyawan di PT Sunrise Polybag.

\section{KESIMPULAN}

Terkait dengan hasil penelitian yang sudah dilakukan, maka peneliti memberikan beberapa saran yang diharapakan dapat bermanfaat. Berikut merupakan saran-saran dari peneliti:

A. Bagi PT. Sunrise Polybag perlu mempertahankan lingkungan kerja yang ada di perusahaan karena lingkungan kerja yang baik terbukti dapat meningkatkan kinerja karyawan secara signifikan. Oleh karena itu, suasana kerja yang kondusif perlu selalu dijaga agar karyawan semakin maksimal dalam bekerja.

B. Bagi penelitian selanjutnya disarankan agar meneliti pada perusahaan yang lebih besar. Hal ini diharapkan bisa meningkatkan kualitas hasil penelitian dan memberikan informasi yang lebih akurat. Selain itu juga bisa memasukkan beberapa variabel lain yang diduga dapat mempengaruhi kinerja karyawan seperti beban kerja, kompetensi, kompensasi non finansial, kepuasan kerja dan sebagainya

\section{DAFTAR PUSTAKA}

A. A Anwar Prabu Mangkunegara, tahun 2006, Perencanaan dan Pengembangan Manajemen Sumber Daya Manusia, Pen. PT Refika Aditama

Agus Ahyari, 1994. Manajemen Produksi, Pengendalian Produksi, Edisi 4. Yogyakarta. BPFE UGM.

Alex S. Nitisemito, (1992), Manajemen dan Sumber Daya Manusia, BPFE UGM, Yogyakarta.

Anwar Prabu Mangkunegara. 2009. Evaluasi Kinerja Sumber Daya Manusia. Bandung: Penerbit Refika Aditama.

Hasibuan, Malayu S.P. 2005. Manajemen Sumber Daya Manusia, Edisi Revisi. Bumi Aksara, Jakarta.

Hasibuan, Melayu S.P. 2010. Manajemen Sumber Daya Manusia. Bandung:Bumi Aksara

Kreitner, Robert and Angelo Kinicki, 2001. Organizational Behavior. Fifth Edition. Irwin McGraw-Hill. 
Rivai, Veithzal dan Sagala, Ella Jauvani. 2009. Manajemen Sumber Daya Manusia untuk Perusahaan dari Teori ke Praktik. Jakarta: PT Raja Grafindo.

Robbins, Stephen P. dan Coulter, Mary. 2010. Manajemen Edisi Kesepuluh. Jakarta: penerbit Erlangga.

Robbins, Stephen, 2006, "Perilaku Organisasi”, Prentice Hall, edisi kesepuluh Sabardini, 2006, "Peningkatan Kinerja Melalui Perilaku Kerja Berdasarkan Kecerdasan Emosional", Telaah Bisnis, Vol.7, No.1.

Samsudin, Sadili. 2009. Manajemen Sumber Daya Manusia. Bandu.ng: Pustaka Setia.

Sarwoto, 1991. Dasar-dasar Organisasi dan Manajemen. Jakarta : Ghalia Indonesia

Sedarmayanti. 2001. Sumber Daya Manusia dan Produktivitas Kerja. Bandung: Mandar Maju.

Wibowo, 2016. Manajemen Kinerja, Edisi Kelima, PT.Rajagrafindo Persada Jakarta-14240.

Yulianti, Eli. 2015. Pengaruh Pelatihan Terhadap Kinerja Karyawan Grand Fatma Hotel Di Tenggorong Kutai Kartanegara. Jurnal Administrasi Bisnis. ISSN 2355-5408 (April). 